Artículo de reflexión

Cuestiones de filosofía

ISSN: 0123-5095

Vol. 2 - No. 19

Julio - dciembre, año 2016

pp. $153-172$

\title{
El multiculturalismo como una opción para generar ciudadanía: un diálogo entre Claude Geffré y Adela Cortina*
}

\author{
Multiculturalism as an alternative to generate \\ citizenship: a dialogue between Claude Greffré \\ and Adela Cortina
}

Álvaro Hernández-Acevedo**
Universidad Santo Tomás

Colombia

Fecha de recepción: 10 de junio de 2016

Fecha de evaluación: 13 de julio de 2016

Fecha de aceptación: 3 de octubre de 2016

* Este trabajo se circunscribe como producto reflexivo y teórico de un proyecto de investigación en curso denominado "Formación de ciudadanos como proceso integral, transversal e incluyente de los jóvenes de Bachillerato y el aporte formativo de la educación superior en la ciudad de Tunja".

** Licenciado en Filosofía Pura. Universidad Santo Tomás, Teólogo del Convento Santo Domingo de Guzmán. Especialista en Pedagogía para la Educación Superior, Universidad Santo Tomás, Villavicencio. Maestrante en Pedagogía, Universidad Santo Tomás, Tunja. Docente de la Universidad Santo Tomás, sede Tunja en el Departamento de Humanidades. Correo: alvaro.hernandez@usantoto.edu.co 


\title{
Resumen
}

Las leyes del mercado le plantean a la sociedad actual las nuevas reglas de vida y de las relaciones humanas, por lo tanto, busca por necesidad, nuevas opciones de convivencia y hasta sobrevivencia, frente a los problemas globales como la pobreza, la desigualdad económica, el terrorismo global, y el sinsentido de una juventud ahistórica. (Bauman, 2009, p. 266). Ante esta situación, la filosofía y la teología deben plantear y generar nuevos espacios de diálogo, análisis y crítica para resignificar el concepto de ciudadanía, relacionado con la dignidad humana y los derechos humanos. En primer lugar, se presentan las condiciones de posibilidad para el multiculturalismo ante la filosofía y la teología, posteriormente una lectura dialógica entre los autores Claude Geffré y Adela Cortina, y, por último, la necesidad de buscar criterios y principios al momento de reconocer la importancia de la búsqueda de la dignidad de la vida humana en un mundo de humanos.

Palabras clave: Multiculturalismo, ciudadanía, diálogo interreligioso, formación ciudadana.

\begin{abstract}
In our societies, human relationships and new rules of life are closely tied to the logic of the market. Society has to look for new alternatives for coexistance and even survival in the face of global issues such as: poverty, inequality, global terrorism and the lack of meaning of an a-historic youth (Bauman, 2009, p.266). In the view of this situation, both philosophy and theology must raise and create new spaces for dialogue, analysis and criticism in order to resignify the concept of citizenship, related to human dignity and human rights. First of all, the conditions of possibility for multiculturalism before philosophy and theology are presented, as well as a dialogic reading between the authors Claude Geffré and Adela Cortina. In this way, it is evident that there is a great need to search for a set of principles and criteria that recognize the importance of the struggle for human dignity in this human world.
\end{abstract}

Key words: Muticulturalism, citizenhip, interreligious dialogue, civic education. 


\section{INTRODUCCIÓN}

El mundo actual donde surgen diversas formas de comunicación, interacción y diálogo con diferentes sujetos con sus imaginarios, hacen que nuestras pretensiones individuales, influenciadas por las leyes consumistas del mercado, superen la incidencia de nuestra responsabilidad, no de cara ya al contexto regional, sino precisamente al global, como ciudadanos del mundo que se nos aparece como nuestra casa. En este feliz encuentro de ideas, sujetos, pensamientos y culturas, la creencia religiosa no está exenta de este diálogo ecológico de saberes. Al respecto, Claude Geffré, teólogo dominico, entiende que en el diálogo interreligioso es una propuesta, una misión y un deber de cada creyente, y más del católico, para que más allá de nuestras convicciones religiosas, busquemos el encuentro con el otro, que nos ayuda a identificarnos, y con lo trascendente, encontrando nuevos valores, pensamientos y respuestas en pro de una sociedad más justa, humana, autónoma y equitativa, en últimas a la experiencia de vivir como ciudadanos. Esta es la gran contribución de este importante teólogo, y por ello se destacarán sus aportes a la reflexión de la vivencia de toda espiritualidad en un contexto social "megadiverso", al que también tiene la misión de decir algo, ya que, todo creyente, que se precie de serlo, debe expresar su vida en coherencia, autonomía, respeto por el otro y lo otro, la búsqueda de un bien común, la defensa de la dignidad de lo humano vivo y de lo no vivo, y además en la convicción de pensar global y actuar localmente.

En este sentido se ubica Adela Cortina, filósofa que ha dedicado, gran parte de su obra, al tema de la ciudadanía, y entre las categorías que desarrolla, reconoce una ciudadanía intercultural, en cuanto que en el ciudadano se consolida la unión entre grupos sociales diversos de manera compleja, pluralista y diferenciada (1997, p. 178). Ahora bien, en este proceso de encuentro con el otro y lo otro, las tradiciones significan con sentido pleno las identidades que permiten construir subjetividades, la convivencia con personas de diversas culturas, definida como multiculturalismo, se concibe como un proyecto político (1997, p. 178). Un elemento fundamental alrededor de esta tipología de ciudadanía es el reconocimiento de la diferencia, referida bien al individuo o bien a la colectividad, lo cual se traduce en consecuencias relacionadas con la justicia. Asílo explicita nuestra autora:

"Dilucidar cuáles deben ser las relaciones entre las diferentes culturas, tanto a nivel nacional como mundial, es una cuestión de justicia" (1997, p.182). 
Siguiendo a Cortina, la interculturalidad exige la vivencia de una ética dialógica que permita identificar al otro en medio de lo otro. La construcción de una convivencia justa y feliz requiere incluir lo antropológico, psicológico, jurídico y político, de tal manera que no se disgregue al más débil, ni se discrimine a las culturas minoritarias y relegadas. Es necesario basarnos en el respeto irrestricto por la autonomía de los individuos que se entienden como codependientes en pro de un mismo proyecto común, con la capacidad de elegir y asumir las consecuencias de dichas elecciones (22 de noviembre de 2005). Por estas razones, es fundamental generar espacios para el diálogo intercultural donde cada cultura aporte los principios, costumbres y pautas en que se respete al otro y lo otro en toda su plenitud, no se asimilen los principios de una cultura dominante, no se asuma la diferencia por la diferencia, que no favorece la construcción de verdades, sino la aceptación acrítica de las personas para evitar molestias futuras.

De ahí que se ubique el aporte de Adela Cortina, a propósito de buscar nexos entre la filosofía y la teología sobre el multiculturalismo, como opción para formar ciudadanos, ya que es en el respeto del otro y lo otro para lograr una autocomprensión como individuos y sujetos de un proyecto común, en que se convierte como elemento fundamental el discurso religioso, puesto que la interpretación y experiencia de la religión genera una comprensión de la cultura en medio de una sociedad dialógica con proyectos comunes con pautas mínimas de convivencia. El multiculturalismo es una apuesta para generar una mentalidad ciudadana, puesto que en el consenso de aquello que nos une, es posible comprender lo que nos puede separar. Los proyectos comunes permiten buscar nuevas soluciones plausibles a esta sociedad globalizada y consumista que quiere anular todo resquicio de humanidad en aras de hacerse totalmente artificial.

La filosofía y la teología, en sus genitivos y sus nuevos paradigmas (Tamayo, 2004), deben repensar esta sociedad enferma que pregona tal dignidad y derechos como bases de su quehacer cotidiano, los cuales nos deberían cubrir a todos los seres humanos. Sin embargo, nuestras pretensiones individuales, influenciadas por las leyes consumistas del mercado, impiden que comprendamos la incidencia de nuestra responsabilidad, no de cara ya al contexto regional, sino precisamente al global, como ciudadanos del mundo que se nos aparece como nuestra casa.

En una sociedad como la nuestra, en la que, por su tradición democrática, se observan y comparten algunos valores, es una necesidad sentida la convicción de vivir bajo una perspectiva moral e ideológicamente plural. Como afirma Adela 
Cortina, con la intención de ir eliminando los presupuestos subjetivistas, "las cuestiones de justicia no dependen de las preferencias de cada sujeto" (19 de marzo de 2003), Esto podría no ser tan difícil de comprender, aunque el reconocimiento de la pluralidad implica la aceptación del otro en todas sus dimensiones, visiones y proyecciones. Cortina, comenta que

"Pluralismo moral" significa que hay discrepancias, pero que desde ellas existen unos valores compartidos en cuestiones de justicia: existe una intersubjetividad ética en valores básicos de justicia. El respeto a la dignidad humana, la defensa de la libertad, igualdad y solidaridad, la valoración del diálogo como medio de resolver los conflictos, el rechazo de la guerra, el fomento del respeto activo hacia posiciones morales razonables, aunque no sean las propias, componen esa ética cívica compartida desde la que tenemos que abordar conjuntamente los problemas morales que nos afectan a todos, e ir construyendo nuestra vida común (19 de marzo de 2003).

Por estas razones, en el propósito de formar una sociedad construida en proyectos de identidad, autonomía, reconciliación y paz, es vital la aceptación del multiculturalismo como expresión válida de un grupo social plural, sistémico y dialógico, en donde el disenso y el consenso son elementos esenciales entre interlocutores válidos por su racionalidad y capacidad de palabra. Este es el objetivo de estas breves reflexiones, guiadas por las ideas que se intentarán colocar en diálogo entre Claude Geffré y Adela Cortina, desde la teología por un lado y la filosofía por el otro, las cuales siguen siendo vigentes en estos momentos de búsqueda de sentido y trascendencia por aquello de lo humano en un mundo de humanos.

\section{PaRa bUSCAR Un CONTEXTo De FORMaCión CIUDADANa Y DE PAZ ES NECESARIO EL DIÁLOGO}

La ciudadanía, según Cortina, se entiende como una forma de ser en el mundo, una condición del ser humano en relación con la sociedad actual que le demanda una postura concreta de pensar, decidir y actuar en diálogo constante (Ascencio, 2012, p. 390) hacia una búsqueda de soluciones plausibles y construidas entre todos. Constituye un estilo de vida que le apuesta a vivir en la construcción conjunta de condiciones en igualdad para el desarrollo integral del ser humano. La ciudadanía hace posible una democracia y un pensamiento democrático que favorece la participación activa, el derecho a tomar decisión en los proyectos comunes, la 
cual exige de cada sujeto la comprensión de vivir ya no en provincias, sino en una aldea global, en donde conviven múltiples culturas, ideologías y pensamientos.

En este horizonte de comprensión, el diálogo se convierte en la condición vital para la comprensión y formación de una sociedad plural y multicultural. Para ello es vital un proceso de formación para la ciudadanía, y como lo expresa Ascencio, los valores se constituyen en la base para la "construcción dialógica de la personalidad moral" (Ascencio, 2004, p. 388), y la estructura para formar sujetos dialógicos para la cooperación (Guillermo Hoyos, 2007, p. 2). Para ello es necesario resignificar cada acto pedagógico y educativo como un proceso de formación en comunidad, en donde cada sujeto entienda y se entienda a sí mismo en su estar-ahí para significar el mundo de la vida de cada uno de ellos.

Cortina afirma que "generar una opinión pública madura y responsable en esa esfera de la discusión abierta debería ser la médula de las sociedades pluralistas" (24 de noviembre de 2004), y la base para ello es la condición dialógica del ser humano, ya que está dotado de competencia comunicativa y con interlocutores válidos (Cortina, 2010, p. 15) que resignifican el mundo. En el hecho de asumir el mundo, se debe comenzar por la comprensión de estar en él, lo cual permitirá construir alternativas emergentes que incluyen discursos, sujetos e instituciones, cuyo objetivo central será formar ciudadanos que piensan, esto es dialogar, en y con el mundo, y actuar en y para el mundo de la vida inmediata. En este proceso, Cortina comenta que es importante "impulsar a través de la educación el desarrollo de la capacidad creadora para que la persona tenga el mayor campo de posibilidades a su alcance" (1995, p. 47). Entonces, el campo educativo y pedagógico debe idear creativamente escenarios de aceptación, no conformista, del mundo en relación con el otro y lo otro a partir de unos ideales y códigos morales que identifican una sociedad.

Un elemento esencial en la realización de este proceso pedagógico, según Cortina, es la formación en la autonomía, que se inicia en el momento biológico humano de auto poseerse, es decir, de la experiencia de saberse dueño de sí en medio de su entorno. Para ello, el hombre necesita un proyecto personal de autoestima y conciencia de que es capaz de poseerlo, diseñarlo y construirlo (1995, p. 49). Este proceso es tarea de la educación y de la pedagogía, donde la autorrealización personal sólo será posible si se entiende en términos de encuentro dialógico con el otro y lo otro, para que no surja el olvido de sí mismo o el egoísmo radical. Así pues, una actitud dialógica implica reconocer al otro como sujeto válido (Ascencio, 
2012, p. 390), porque es un sujeto capaz del lenguaje y la palabra, de escuchar al otro y lo otro como "sujetos vivos" con quienes se puede construir una realidad y verdad nuevas y transformadas, buscando lo que se tiene en común.

Para Cortina, la educación moral del ciudadano consiste en "formar a los niños como hombres e interesarles más tarde en los valores de la ciudadanía" (1995, p. 51), mediante políticas, prácticas y discursos en donde el niño se sienta aceptado por la comunidad, motivado por una calidad de vida e interpelado a coexistir interculturalmente y sin prejuicios con los demás. De esta manera se forma con identidad y sentido de pertenencia. Se hace hincapié en los beneficios de formar en ciudadanía en relación con la moral, puesto que lleva a que surja, naturalmente, un desarrollo de la madurez moral del individuo, porque lo saca de su zona de confort y lo confronta con su ambiente vital, además que lo forma en su subjetividad, aprende a solucionar conflictos y construye comunidades democráticas con solidaridad generacional. De ahí que Hoyos comente que "en el proceso educativo la manera como se comprenda la sensibilidad moral es definitiva para la formación de la persona" (2011, p. 4), en donde se incluye persona, sociedad y cultura, mediados por eldiálogo que posibilita un multiculturalismo liberador y transformador del mundo de la vida de cada ser humano que cohabita con el otro y lo otro.

Cortina establece que es necesario tener en cuenta la dimensión lógico-formal de la razón en cuanto que posibilita ser capaz de elevar pretensiones de validez del habla y resolverlas a través de un discurso. Es necesario situar los universales del habla en los procesos de comunicación para decidir en situaciones de justicia la aceptación mutua con interlocutores válidos. Esto permite argumentar por medio de la estimación de valores, la condición del ser humano, y así formar juicios a través de la adquisición de las virtudes. De ahí que "si no se estima el valor de la justicia ni siquiera importa que una norma sea justa" (Cortina, 2010, p. 17). Así pues, el diálogo es condición necesaria para formar un conjunto de competencias que permitan ser autónomos para elevar esas pretensiones de validez para aceptar, rechazar y optar por intereses que puedan ser universales, y formarse un juicio moral con el fin de llevar una vida digna de ser vivida.

Ahora bien, Cortina afirma que el diálogo es la relación entre sujetos racionales y capaces de palabra, que expresan una racionalidad comunicativa, dado que se llega a posibles acuerdos mediante argumentaciones que involucran la vida entera de cada ciudadano. En este sentido, el interlocutor es un sujeto con el que se puede llegar a cumplir ideales con carácter universal, y la pedagogía debe considerar 
personas que son formadas en una actitud dialógica, que la autora caracteriza de la siguiente forma:

- Reconoce a las demás personas como interlocutores válidos, con derecho a expresar sus intereses y a defenderlos con argumentos.

- Está dispuesta igualmente a expresar sus intereses y a presentar los argumentos que sean necesarios.

- No cree tener ya toda la verdad clara, de suerte que el interlocutor es un sujeto a quien convencer, no alguien con quien dialogar. Un diálogo es bilateral, no unilateral.

- Está preocupado por encontrar una solución correcta y, por tanto, por entenderse con su interlocutor. "Entenderse" no significa lograr un acuerdo total, pero sí descubrir lo que es común a todos.

- Sabe que la decisión final, para ser correcta, no tiene que atender a intereses individuales o grupales, sino a intereses de carácter universal, es decir, a aquello que “todos podrían querer", por decirlo con la célebre fórmula del contrato social.

- Sabe que las decisiones morales no se toman por mayoría, porque la mayoría es una regla política, sino desde el acuerdo de todos los afectados porque satisface asimismo los intereses de todos (1995, p. 58).

'Estas características permiten deducir fácilmente el papel de la formación, la educación y la pedagogía, en aras de la configuración de sociedades democráticas y ciudadanas, y su eje estructural es el diálogo. En este marco de comprensión, la formación en ciudadanía está mediada por la construcción de espacios dialógicos en los que cada sujeto se identifique con el grupo social, en los que se deben desarrollar procesos de educación en sentimientos y emociones, el contexto en que se viven los valores, en hábitos que forman virtudes, en el autocontrol, en el autoconocimiento y autoestima, en la empatía, el juicio y la conciencia morales, y en la posibilidad de apertura de sentido (Puig, 1998, p. 23), el cual abre las condiciones para una formación hacia la apuesta por la trascendencia y la búsqueda de sentido. En este último aspecto, la educación debe estar abierta, tanto en las políticas como en la práctica, a la categoría antropológica de la trascendencia, en cuanto capacidad compleja del ser humano de abrirse a relaciones que superan la racionalidad humana y a la vez que pueden ser comprendidas por el hombre que busca un sentido ulterior a su existencia y lo dispone al diálogo con el otro.

Desde esta convicción, se asume como condición necesaria al diálogo, y la emergente teología del diálogo interreligioso comprende, que un proceso de diálogo se inicia cuando se elimina nuestra pretensión de convertir al otro, es decir, de 
conminarlo a que asuma nuestras ideologías, creencias o pre comprensiones (Fornet, 2007, p. 20). En este sentido, es necesario conocer el horizonte de las tradiciones, verdades y ritos de las demás religiones para generar un ambiente de diálogo a fin de encontrar en las culturas el contexto histórico donde lo divino se revela de múltiples formas, generando una identidad propia de cada vivencia religiosa y trascedente. Por tal razón, el mensaje cristiano debe ser transcultural y transhistórico a todas las tradiciones y contextos geográficos, favoreciendo así el policentrismo cristiano, donde las expresiones vivas de cada experiencia cristiana tengan su validez y no sustentarse desde la perspectiva exclusivista de Roma. Entonces, el multiculturalismo se convierte en una estrategia esencial para entender al otro en todas sus dimensiones, intereses y pretensiones, puesto que allí es que nos autoidentificamos y autocomprendemos para generar espacios de diálogo hacia un entorno democrático, pacífico y autónomo.

Geffré y Fornet afirman que la religión no puede seguirse concibiendo como una empresa expansionista de salvación, negadora y excluyente de toda pluralidad y diferencia, y que la monoculturalidad es una limitante para el desarrollo de las potencialidades de la fe cristiana (Fornet, 2007, p. 29). Nosotros afirmamos que todo diálogo interreligioso sólo será posible si superamos esta limitante, en la medida que aceptemos al otro en su especificidad y así lograremos fortalecer nuestra identidad religiosa, a partir de un pluralismo de principio donde comprendemos que la experiencia religiosa, desde cualquier confesión, es un designio misterioso de Dios que se revela a los hombres del mundo.

Ahora bien, Adela Cortina entiende que, aunque la condición religiosa es necesaria para formar entornos ciudadanos y, por lo tanto democráticos, no responde a la visión cristiana solamente, sino que lo hace desde una mirada más amplia de la dimensión religiosa del ser humano en cuanto tal, aunque sí está de acuerdo en que la cultura no es la que posee la verdad religiosa, sino que radica en el construir juntos una nueva cultura donde se salvaguarde cada principio y se edifique la defensa de toda vida. Esta cultura será el resultado de un proceso de constantes cambios y su verdad no sería catalogada como la única, pues su manera de ver el mundo es contingente, lo que permitirá eliminar todo complejo de superioridad y así entrar en la dinámica dialógica y democrática.

Geffré y Cortina están de acuerdo en que dialogar con el otro no implica adaptarse a los fundamentos de la fe de las religiones, ni crear espacios culturales en cuanto que promuevan el ecumenismo, sino que es un crecimiento plural desde la diversidad 
de las mismas y, muy especialmente, desde las prácticas cotidianas en que se expresa en concreto el pluralismo cultural. Y así mismo, la educación debe procurar esos espacios.

\section{URGENCIA POR LA EMERGENCIA DE UN MULTICULTURALISMO}

Ante los desarrollos económicos y tecnológicos que han generado destrucción hasta el punto de poner en riesgo la supervivencia de la humanidad, es una urgencia global que se genere una ética. Esta debe plantear los principios por los cuales todos los habitantes se hallen interpelados en su conciencia y en su ser relacional, tanto con el otro, y éste un igual, como con el medio ambiente, pues este cambio de paradigma hacia la bios como centro, "es un camino que todo ser humano debe iniciar en pro de buscar ese equilibrio de auto coorganización" como lo dijera Maturana (2009, p. 10). Esto se traduce en derechos a una vida digna de lo humano y no humano. Según Kymlicka (1995), es esencial el respeto por las minorías etnoculturales y el reconocimiento de una ciudadanía diferenciada, en la que las minorías sean reconocidas, no desde una cultura dominante, sino desde sí mismas, ya que poseen sus propios constructos ideológicos, culturales, políticos y sociales (Elosegui I., 1997, p. 23).

La situación actual del ser humano en busca de una convivencia pacífica y tolerante, exige que asuma responsablemente una ética planetaria, en la que comprenda que es cohabitante con su congénere y con el ambiente, y que a ellos debe una determinada dependencia que le permite lograr su autorrealización y auto identificación; de tal forma que esa ética que, hasta el momento no se ha hablado de cómo se entiende, se están presentando contextualmente, algunas pistas de análisis. Lo que sí se puede expresar, hasta el momento, es que no se puede concebir una ética como "técnica de reparación de deficiencias y correcciones" (Küng, 1991, p. 55).

Adela Cortina comenta que el multiculturalismo es el hecho de que en un mismo espacio social convivan personas con distintos bagajes culturales, sin embargo el aumento de inmigrantes, el incremento de las negociaciones internacionales, y la influencia globalizante de los medios de comunicación, generan nuevos espacios

sociales con nuevas soluciones a problemas, ya de orden global, se convierten en tarea compartida por todos los ciudadanos del mundo, admitiendo una interdependencia para converger la diversidad de culturas con las exigencias de justicia (22 de noviembre de 2005). 
Tanto Geffré como Cortina asumen que el multiculturalismo es una opción para formar ciudadanía en la medida que posibilita espacios de diálogo, interdependencia, evitando la tentación de la segregación, de absorción de una cultura débil o minoritaria, o en el peor de los casos la discriminación de ciudadanos de primera y de segunda. La sociedad actual vista desde la filosofía o la teología debe tener como principios fundamentales el trato mutuo con igual consideración y respeto, reconociendo la dignidad de cada ser vivo, estimar al otro en todas sus dimensiones y en sus derechos individuales como expresión última de su autonomía que es irrenunciable. De ahí que el diálogo intercultural sea imprescindible, y Cortina establece dos supuestos básicos: importa respetar las culturas porque los individuos se identifican y estiman desde ellas y no se puede renunciar a priori a la riqueza que una cultura pueda aportar, pero a la vez ese respeto tiene que llevar a un diálogo desde el que los ciudadanos puedan discernir qué valores y costumbres merece la pena reforzar y cuáles obviar (Cortina, 2005) en la vida cotidiana, la cual es el verdadero e importante contexto para generar un diálogo inter y multicultural.

\section{EL FIN Y EL CRITERIO: EL HOMBRE}

Es bueno que el hombre atienda más hacia lo humano, al hecho de promover su humanidad, y que su sociedad sea cada vez más humana, esto es, en la constante búsqueda de la perfección de todas sus condiciones y dimensiones, incluso en relación con su medio ambiente; de ahí que haga mención Küng que el principio responsabilidad y el utópico de la esperanza de Ernest Bloch vayan a la par en un contexto donde la solidaridad planetaria se exige como conditio sine qua non la supervivencia de lo humano (Küng, 1991, p. 62).

Esta visión de reconocimiento de lo otro, de una ética de la alteridad en función de una ética planetaria, no da lugar a que la autodeterminación, a que toda experiencia personal, descubrimiento y realización de símismo no sean posibles. No se pretende anular la condición de lo individual, sino todo lo contrario, en la medida que el hombre se reconoce como un ser igual al otro y entra en diálogo con él, se va autoidentificando y logrando su autonomía y autenticidad.

Aunque tampoco se pretende una degeneración narcisista de introvertirse como un autista socialmente aceptable. Afirma Küng que "la generación de un mundo mejor requiere identidad y solidaridad" (1991, p. 65). De ahí que el hombre jamás

deba ser concebido como un medio sino como un fin, y sí deben "ser medios para 
ese criterio y fin, el trabajo, la ciencia, la técnica y la industria”, esto es, deben dar respuesta con valores para actuar en contexto que humanicen al mismo ser humano y su entorno vital. Este es el presupuesto fundamental del multiculturalismo, en cuanto que, en la medida que, al reconocer la total dimensión del otro, es que se podrá concebir un entorno de paz, reconciliación, autonomía y democracia.

Desde la perspectiva teológica, la mentalidad moderna, acerca de la religión y de su relación con la sociedad, ha enseñado que la moral puede estar sustentada en la misma razón humana o lo que posteriormente se ha asumido que la dignidad humana es el fundamento moral del actuar, ya que así todos los habitantes de este planeta pueden comprender y definir su comportamiento sin tener en cuenta la divergencia religiosa que todas las sociedades están experimentando. De tal forma que previene así el peligro de una vida sin sentido (Küng, 72). En esta forma, se genera una mentalidad de responsabilidad con el otro, lo que permite una conciencia de consenso hacia una democracia efectiva y planetaria que defienda, promueva y proteja la dignidad humana.

Küng y Geffré reconocen que el hombre religioso de hoy tendrá que asumir una conciencia de diálogo interreligioso y, podría decirse, intercultural (Küng, 1991, p. 87), en vista de que deberá buscar soluciones a las problemáticas del mundo actual, en el que todo creyente se halla involucrado y, por tanto, es responsable, desde la moral que va reinterpretando, con sus experiencias y diversidad de expresiones que su confesión le brinda, en ese proceso de conocimiento del otro y de autoidentificación.

A propósito Geffré propone un modelo intercultural, en el que se puede afirmar que el diálogo interreligioso e intercultural será más que todo una conversación, un reencuentro creativo teniendo en cuenta que todo resultado es imprevisible y que las raíces del cristianismo parten de una cultura concreta como es la griega. Ante estas variables, el cristianismo, generador de occidente, deberá entrar en diálogo con otras fuentes que pertenecen a distintas fuentes tradicionales de otras civilizaciones (1999, p. 101).

Afirma que, en los eventos humanos, en los que la gracia divina participa en esa historia y la convierte en un hecho salvífico, en virtud de la comprensión trascendental de la que es capaz el hombre para leer su historia como un diálogo con lo divino. La capacidad racional del hombre se ve motivada, en su evento histórico, a identificar la realidad como contexto de la Palabra, y asímismo como interlocutores 
de un mensaje lleno de la gracia divina impregnado de justicia, libertad, igualdad y servicio (Geffré, 1999, p. 109). A esto Cortina aportaría que son valores que resulta imposible indoctrinar, porque por su misma naturaleza educan para forjarse un universo abierto, ya que pertenecen al universo de la justicia, que es el quicio de la ética ciudadana (Cortina, 26 de junio de 2006).

La teología de Geffré es comprender la palabra que humanamente habla de Dios y no un discurso sobre Dios (1999, p. 14). Es importante anotar que "el lenguaje es una forma privilegiada de captar la realidad, de manera especial, trascendente, pues una lengua puede trascender por sí misma" (2007, p. 48), de ahí que sea vital la hermenéutica en la medida que la palabra escrita humana no agota el misterio ni está encerrado en ella, sino que se va descubriendo por mediación de la historia y las demás ciencias que permiten la aclaración de lo dicho allí, del misterio que se va haciendo descriptible en la experiencia humana creyente.

Ahora bien, Geffré establece que la relación del cristianismo con la sociedad pluralista y democrática debe estar bajo los principios de igualdad y nunca utilizar el argumento de autoridad sobre la vida interna y la conciencia del ciudadano, puesto que el criterio de la verdadera cultura es la promoción del ser humano auténtico. En el programa de las bienaventuranzas se expresa la necesidad de las fuentes culturales y de otras tradiciones religiosas hacia la mundialización: la hospitalidad musulmana, la no violencia hindú, la compasión budista son ejemplos del proyecto planteado por Jesús en las Bienaventuranzas.

El pluralismo religioso es un fenómeno social en cuanto que toda confesión, espiritualidad, movimiento religioso se han dado a la tarea de buscar mecanismos y estrategias para lograr encuentros y puntos de unión con las demás, a fin de hallar en sí mismas su propia identidad y la construcción en conjunto de un sentido de la existencia para todos y cada uno de los seres humanos de este planeta tierra. También es un lugar teológico en el que los teólogos como Geffré se han dado a la tarea de encontrar aquellas categorías hermenéuticas que permitan un diálogo desde los mismos fundamentos, sin pretensiones de convencimiento ni de sometimiento frente a una verdad que todos creerían tener (1999, p. 156ss).

Nuestro autor comenta que "la verdadera misión en un sentido de diálogo interreligioso se entiende en el hecho que se debe ayudar a que los hombres y mujeres sean más fieles a su propia religión". No se debe entender como la búsqueda implacable del convencimiento de la posesión de la verdad o del depósito 
absoluto de la fe, sino todo lo contrario, al hecho de que cada uno debe buscar la identidad y la fidelidad a su fe (Geffré, 1999, p. 171). Asíen la identidad y seguridad en símismos, se podrá generar un proceso multicultural, democrático y de progreso, pues cada ciudadano construirá un proyecto que favorezca al ser humano.

Las diferentes religiones históricas, en el momento actual, tienen que entrar en diálogo con la gran variedad de confesiones y espiritualidades, teniendo en cuenta los presupuestos morales que las han sostenido desde sus libros y experiencias fontales. En las dinámicas sociales de hoy, deben responder a las necesidades y urgencias del hombre moderno, es decir, iniciar un proceso hermenéutico serio, o de lo contrario será un compendio normativo que sustentaría pasivamente la religión privada de cada creyente (Küng, 1991, p.86).

\section{LA RELIGIÓN Y LA CIUDADANÍA AL SERVICIO DE LO HUMANO}

Se reconoce que la religión es un sistema de orientación en cuanto brinda un sentido de la existencia y una determinación moral, aunque en una época de incontestable secularización, es importante, pues sigue cumpliendo esta función (Küng,1991, p. 68). En el momento en que se comprenda como un dispositivo de cohesión social, y al quedarse ahí, en estos procesos evolutivos culturales y científicos, se muestra anquilosada rayando en lo retrógrado y que, por lo tanto, ha perdido su razón de ser en la vida del hombre. Actualmente, la religión debe cumplir su misión de ser formadora social, es decir, de aquella expresión humana que le permite al ser humano comprender su experiencia con lo trascendente en función de transformar su entorno en términos de justicia, equidad, autonomía, libertad y amor, en fin, de formar al ser humano, con su testimonio, creyente o no creyente en mentalidad democrática que busque lo auténticamente humano.

La diversidad cultural es el ideal democrático de todo individuo que comprende su mundo de manera abierta y en función de parámetros que pueden dar cabida a visiones diversas y de corte religioso radicalmente distinto. En esta diversidad se parte del presupuesto de la separación de la religión con la política, puesto que es un error politizar la religión y oponerse a la secularización. Es vital fundamentarse en el principio de los Derechos Humanos, que son elementales para todo ser humano en la medida que los cubre y no permiten asimilarse desde una perspectiva religiosa, sino desde la estricta igualdad (Geffré, 1999, p. 29). La religión debe ser más que una fuerza de cohesión social. No puede concebirse como religión vacía, como una creencia individual, como utopía mobiliaria. 
Ahora bien, Geffré comenta que la secularización es un fenómeno por el cual las realidades del hombre y del mundo tienden a establecer una autonomía cada vez mayor, dejando a un lado cualquier referencia religiosa. Posee tres etapas: 1. Laicización que es el proceso de emancipación de la sociedad moderna, que genera (2) la desacralización, considerada como el momento en el que el mundo y lo humano pierden su valor sagrado y readquieren un valor mundano y natural, de tal forma que se va consolidando un (3) ateísmo donde se va emancipando el hombre y la mujer modernos en relación con Dios. Geffré trata de articular fe y religión, en la medida que establece lo "sagrado original" del hombre como misterio de apertura y comunión, en cuanto que lo humano es el lugar originario de la revelación de lo sagrado, el cual se va comprendiendo cultural e interculturalmente.

En este sentido, en su trabajo teológico del diálogo interreligioso y más aún en el intercultural, la historia como contexto de todas las culturas es fundamental a la hora de comprender la experiencia religiosa humana, con el fin de entablar procesos en donde cada religión que, ahora ya no está circunscrita a un espacio definido y único, es necesario resignificar la experiencia fontal de cada confesión y actualizarla según el momento actual, de tal forma que el mensaje pueda ser comprendido por las nuevas mentalidades y, en el diálogo, se asuma cada vez más la identidad de cada religión (Croire et interpréter, 99). Además, invita a que se convierta en una religión dialogal. Por tanto, si Dios se hace histórico, relativo, el cristianismo no puede contrariar este hecho misterioso haciéndose absoluta. Así, bajo esta conciencia y con la búsqueda de una universalización que no significa mundialización, es que podrá establecer un diálogo intercultural, representando cada centro donde se vive la experiencia de Jesús el Cristo.

Claude Geffré habla de un ecumenismo planetario en la medida que actualmente todo habitante de este planeta se siente que vive en una misma casa común y hasta en una misma familia (1999, p. 121). Es un diálogo interreligioso con las distintas denominaciones religiosas del planeta que reflejan en sus ritos, ideologías, creencias, culturas, dogmas y libros la experiencia con el Absoluto que nos une como seres humanos creyentes. Para tal efecto, Geffré se preocupa por integrar en este diálogo, las herramientas tecnológicas para ir hallando trazos que vayan uniendo culturas partiendo de las mismas religiones.

En el propósito de buscar un criterio que valide ese ecumenismo planetario, Geffré destaca que debe ser de tipo ético y místico, ubicando en estas categorías lo auténticamente humano, en cuanto que procura que todas las religiones busquen la 
libertad y la felicidad de las personas. Místico porque revela la apertura y la condición de la que hablara Rahner del existencial sobrenatural, su capacidad de abrirse a lo Trascendente. Por eso afirma que "siempre se constata una relación de alteridad, la cual corresponde un fundamentum en el ser humano” (1999, p. 106).

Este criterio de lo auténticamente humano es un principio fundamental para lograr ese diálogo intercultural en cuanto que potencia y valoriza al ser humano en todas sus dimensiones. Así, lo que fundamenta las religiones es la experiencia en y con Dios iniciada por Él mismo, pues es Creador del ser humano y la responsabilidad por su cuidado es de todos que somos cocreadores de este mundo, porque lo que urge es resolver el problema de la miseria, integrar a los que huyen de ella, dialogar con su cultura y hacer creíble con la acción que el respeto a los derechos humanos es un buen programa ético-político (Cortina, 2005).

\section{ConClusiones A MOdo de REFleXiones PROYECTIVAS}

En los momentos en los que el multiculturalismo se convierte en una de las aristas de los nuevos paradigmas ecocéntricos o si se quiere del biocentrismo, se hace imprescindible realizar el ejercicio de auto comprendernos en el diálogo con el otro, sin pretensiones de absorción o con prejuicios de ciudadanías de segunda, además de sentirnos alegres de un proyecto de nación, puesto que, como dice Rorty "no podemos siquiera encauzar una crítica constructiva a nosotros mismos si no nos alegramos de nuestra identidad...", afirmándolo del caso norteamericano que busca siempre formar en ese orgullo nacional (1997, p. 36). De ahí que un pensamiento como ciudadano del mundo le va a dar a la región una nueva perspectiva incluyente y dialogante, en aras de construir eso que hemos denominado proyecto de nación, donde se vinculan todas las necesidades en justicia de los otros, las cuales van a permitir definir las metas nacionales, que no deben reñir con los intereses de cada individuo o región.

La construcción de entornos y espacios en donde surja una mayor participación de ciudadanos de primera categoría, la vivencia del respeto de los Derechos Humanos y la configuración de prácticas pedagógicas que den relevancia a la alteridad como fundamento antropológico de base, se convierten en categorías esenciales para una sociedad más justa, equitativa, incluyente y democrática. Sin embargo, este ideal de sociedad, que la llevará a un nivel de comprensión del mundo de orden cosmopolita y, por lo tanto, global, hará que sus ciudadanos asuman su papel de formandos y luego formadores en ciudadanía, a través de la 
realización de proyectos de participación política que respondan a los retos del desarrollo sostenible y de una sociedad plural, diversa y tolerante que promueva el progreso integral del hombre y del mundo de lo humano.

El ser humano, al ser imagen de Dios, está llamado a establecer una relación dialogal e íntima con Dios. En sí mismo tiene la posibilidad de experimentar los mismos sentimientos de Dios Padre, que cuida de sus creaturas, y por lo tanto, es indigno y pecaminoso el hecho de que el hombre no cuide de su entorno, de sus congéneres y de su misma unión con Dios. En este sentido, ya desde el Génesis se le encomendó la tarea de cuidar su entorno, y así la naturaleza cobra un sentido mayor que el de proveedor de recursos, ya que por ella, el hombre se adhiere a su terruño, lo identifica, lo compenetra hasta sentir los mismos dinamismos que le fueron dados. De ahí que no sea exagerado entender la naturaleza como un sacramento, pues es el signo visible del don de Dios a los hombres. Entonces, en estos tiempos, es momento de resignificar nuestra espiritualidad como la unión íntima y dialógica con Dios, que se traduce en actos de cuidado de sí mismo, del otro que es su igual, y del medio ambiente donde coexistimos como una comunidad viva que anhela una mayor calidad y dignidad.

La filosofía y la teología como ciencias sociales deben generar espacios de reflexión académica, investigativa y de proyección de lo humano en todas sus dimensiones sin seguir los criterios cientificistas y economicistas del sistema hegemónico actual. Deben seguir en la reflexión que busca soluciones integradoras de los demás saberes e incluir a todos los menos favorecidos en este sistema perverso, y atender a los nuevos paradigmas que los acontecimientos geográficos, biológicos y políticoeconómicos están propiciando: el biocentrismo. Sin ánimo de extender más este texto, es importante acudir a este paradigma emergente que incluye la totalidad de las dimensiones del ser humano y tiene su expresión en la vivencia de una ciudadanía en contextos globales y multiculturales. Es así que la educación debe generar espacios y estrategias para equilibrar y desestabilizar las estructuras del conocimiento, y darles signos con significado pleno para que pueda resolver los problemas de su entorno inmediato. Para generar procesos de resolución de problemas es vital la percepción y la función cognitiva necesaria en el pensamiento flexible, donde se incluyan en los currículos las formas vivas no humanas, y por ello el biocentrismo empieza a hacer efecto en los nuevos paradigmas de la construcción de conocimiento y de las cosmovisiones y epistemologías.

El biocentrismo se debe entender en varios ejes: la vida, el universo, lo vivo humano y lo vivo no humano para intentar comprender la totalidad de lo real de manera 
interdisciplinar, intercultural; entre lo vivo humano y la vida se evidencian las racionalidades, ya que no solamente existe como única la occidental. Entre la vida y lo vivo no humano se deben vincular los sentires; entre lo vivo no humano y el universo aflora la biosofía que supera la condición de lo humano para que éste siga sobreviviendo. Ahora, entre lo vivo humano y el universo surgen las cosmologías: estas relaciones tensionantes exigen la generación de una nueva educación. Es necesario romper la racionalidad y el sentir eurocéntrico para poder incluir lo vivo no humano que tiene los mismos derechos, gracias a la vinculación de los sentires que incluyen lo moral, lo político y lo económico en pro de la supervivencia del mundo de la vida.

Entre las racionalidades y los sentires se construyen las incertidumbres como horizonte de comprensión para la educación, y los sentires y la biosofía permiten construir las alteridades de respeto del otro y lo otro para dejar a un lado el discurso vacío de la interculturalidad. Las biosofías y las cosmologías nos permiten comprender la multidimensionalidad en que se debe entender la vida plena. En la tensión cosmologías y racionalidades surge el caosmos (Guattari, 1996) como "comprensión del desorden como estado natural de las cosas"; entre éste y las incertidumbres suceden los constantes reinicios del ser humano que eliminan el estado de confort; entre las incertidumbres y las alteridades surgen unas nuevas epistemologías; entre las alteridades y lo multidimensional surge un nuevo sujeto entendido como macrosujeto que entiende la singularidad en medio de un sistema más grande; y entre el caosmos y lo multidimensional surge los ciudadanos "cuánticos"2.

Entre el reinicio y las nuevas epistemologías aparece una nueva paradoja definida como ignorancia que se pretende saber todo y no se sabe nada; entre nuevas epistemologías y el macrosujeto surge otra paradoja, la individualidad; entre los ciudadanos cuánticos y éste macrosujeto surge la paradoja de la ciudadanía; y entre el reinicio y los ciudadanos cuánticos surge la paradoja de la vivencia en un nuevo mundo de la vida que insta para ser humanizado en un mundo de humanos.

Las comillas son nuestras.

2 Categoría emergente que alude a la complejidad del ser humano en sí mismo en relación con los demás sistemas de lo vivo humano y no humano, en donde la relacionalidad, incertidumbre y complementariedad redundan en la dinámica humana y social. 


\section{REFERENCIAS}

Ascencio A., S. (2012). Educación para la ciudadanía: una mirada desde la ética del discurso. En: Derechos y humanidades. Num.19. Universidad de Chile, Santiago de Chile.

Bauman, Z. (2009). Ética posmoderna. Siglo XXI editores, Madrid.

Cortina, A. (2003, 19 de marzo). Pluralismo moral y células troncales. El País. Recuperado de http://elpais.com/diario/2003/03/19/opinion/ 1048028409_850215.html

(2004, 24 de noviembre). Ciudadanía Mediática. El País. Recuperado de http://elpais.com/diario/2004/11/24/opinion/ 1101250805_850215.html

(2006, 20 de junio). Educar en una ciudadanía justa. El País. Recuperado de http://elpais.com/diario/2006/06/20/opinion/ 1150754414_850215.html

(2005, 22 de noviembre). Europa intercultural. El País. Recuperado de http://elpais.com/diario/2005/11/22/opinion/ 1132614008_850215.html

(2010). Justicia Cordial. Minima Trotta, Madrid.

Elosegui I., M. (1997). Kymlicka: en pro de una ciudadanía diferenciada. En: Revista Doxa, Num. 20, Alicante.

Fornet-Betancourt, R. (2007). Interculturalidad y religión. Para lectura intercultural de la crisis actual del Cristianismo. Quito, Ediciones Abya- Yala.

Geffré, C. (1999). Profesion theologien. Quelle pensée chretienne pour le xxie siécle. Entretiens avec Gwendoline Jarczyk. Ediciones Albin Michel, Paris. (1999). Croire et interpréter. Editions du Cerf, Paris.

Guattari, Félix (1996). Caosmosis. Manantial, Buenos Aires.

Hoyos, G. (2007). Comunicación, educación y ciudadanía. Conferencia inaugural. Maestría en educación 21 de agosto. Universidad del Valle. Instituto de educación y pedagogía. Cali. 
(2011). Educación y ética para una ciudadanía cosmopolita. En: Revista Iberoamericana. Núm. 55, enero-abril.

Küng, H. (1991). Projet d'éthique planétaire. La paix mondiale para la paix entre les religions. Traduit de l'allemand par Joseph Feisthauer Ediciones du seuil, Paris.

Kymlicka, W. (1996). Ciudadanía multicultural. Editorial Paidós, Madrid.

Maturana, H. (2009). La realidad: ¿objetiva o construida? Fundamentos biológicos de la realidad. Anthropos, México.

Nussbaum, M., Rorty, R., Rusconi, G. E., Viroli, M. (1997). Cosmopolitas o patriotas. Fondo de Cultura Económica, Buenos Aires.

Panasiewicz, R. (2007). Pluralismo religioso contemporneo. Diálogo inter-religioso na teología de Claude Geffré. Ediciones Paulinas, Sao Paulo.

Puig Rovira, J.M., Martin García X., (1998). La educación moral en la escuela. Teoría y práctica. Editorial Edebé, Barcelona.

Rahner, K. (1977). Curso fundamental de la fe. Introducción al concepto de cristianismo. Herder, Barcelona.

Rorty, R. (1997). Contingencia, ironía y solidaridad, Paidós, Barcelona.

Tamayo-Acosta, J. J. (2004). Nuevo paradigma teológico. Trotta, Madrid. 